\title{
ANALYSIS OF POWER EFFICIENCY OF A DIRECT-DRIVEN LOCALLY FABRICATED PERMANENT MAGNET AC GENERATOR FOR SMALL-SCALE WIND POWER APPLICATIONS IN TANZANIA
}

\author{
R.A. Msuya ${ }^{1}$, R.R.M. Kainkwa', M.I. Mgwatu ${ }^{2}$ \\ ${ }^{1}$ Departrment of Physics, College of Natural and Applied Sciences, \\ University of Dar es Salaam, Tanzania \\ ${ }^{2}$ Department of Mechanical and Industrial Engineering, College of \\ Engineering and Technology, University of Dar es Salaam, Tanzania
}

\begin{abstract}
The use of direct-driven permanent magnet alternating current (AC) generators offers the opportunity to reduced costs and increased system efficiency. This type of generator could be the best alternative for rural population whom are not connected to the national grid. To improve the design and efficiency of locally fabricated generators, it is imperative to characterize both their mechanical and electrical parameters. This paper presents the analysis of power efficiency of the synchronous permanent AC generator locally fabricated in Tanzania. In this case, load resistance and rotational speed are characterized using designed experiment. The output current and voltage of the generator were recorded simultaneously in each step change of load resistance and rotational speed. The output power and efficiency were then determined analytically. The results show that there is a linear relationship between voltage and rotational speed of the generator with and without load resistance. The results further indicated that out power is not linearly related to rotational speed. The generator's power efficiency was found to be about 55\% against both the output voltage and rotational speed.
\end{abstract}

Keywords: Wind power efficiency, permanent magnet ac generator, experimental design.

\section{INTRODUCTION}

Wind turbine generators as electrical machines are usually divided into three major groups known as direct current (DC) machines, asynchronous alternative current $(\mathrm{AC})$ machines and synchronous AC machines. Currently, DC machines are not widely used due to high maintenance costs associated with them. In most cases, the load winding of $\mathrm{AC}$ generators consists of three phases (Hansen at el., 2001). In this paper, discussion and analysis will involve permanent magnet AC wind generator, three phase machine with an outer stator carrying the main (primary) winding. The rotor is arranged inside the stator with permanent magnet, and the air gap separating the inner part of the stator and outer rotor surfaces. The interacting magnetic field crossing the air gap is in radial direction couples stator and rotor.

The major characteristics of a permanent magnet generator (PMG) is that the magnetization in the windings is provided by a permanent magnet pole system on the rotor, instead of taking excitation current from the armature winding terminals as in other types of generators like Induction Generator (IG). This means that the mode of operation is synchronous, as opposed to asynchronous. Therefore, the output frequency of PMG 
bears a constant relationship to the shaft speed. Almost all electrical power generated by three-phase a.c. generators are synchronized with the utility to the end user. A three-phase generator in most cases are smaller, less expensive, and more efficient as compared to singlephase generator of the same power. This shows the importance of using three phase generator whenever possible (Johnson, 2006). The main advantage of permanent magnet synchronous generators over other generators is due to the fact that it does not require any external excitation current, which translates in a significant decrease in rotor losses. Furthermore, permanent magnet machines have high torque than other type of generator of same size and can be designed in many different configurations. This type of wind generators is mostly used in small scale wind harvesting system using permanent magnet synchronous generators.

The type of generator considered in this study is the direct driven PMG three phase AC machine with maximum power of $1000 \mathrm{~W}$. Typical sizes that are manufactured in industries of this type of generators range between $250 \mathrm{~W}$ and 2 $\mathrm{kW}$. Small scale wind turbine generator system in most cases operates in low wind speed efficiently from $3.5 \mathrm{~m} / \mathrm{s}$. This system is a variable-speed as wind speed varies with time.

The extractable wind power, $P_{e}$, is described by equation (1) (Johnson, 2006):

$P_{e}=\frac{1}{2} \rho A V^{3} C_{p}$

where $\rho$ is the density of air, $V$ is wind speed available to the rotor, $A$ is the cross sectional area of rotor and $C_{p}$ is the efficiency of the wind turbine. The theoretical maximum value of $C_{p}$ is 0.59 , but the practical limit is 0.5 , attaining $C_{p}$ above 0.4 is considered good (Stiebler, 2008 and Vongmanee, 2009). The maximum power that can be extracted by a Wind Energy Conversion System (WECS) is $59.3 \%$ of the total available wind power (Johnson, 2006). Practical values range between $25 \%$ and $30 \%$. This is due to wind speed variation, type of WECS and the type of applied resistive load. The power in the wind is converted to mechanical power which is transmitted to the generator through a mechanical transmission power, $P_{i}$, which is then converted to electricity with an electrical power $P_{o}$. The generator's power output efficiency $\eta$ can be expressed as:

$\eta=\frac{P_{o}}{P_{i}} \times 100 \%$

A generator that is directly connected to the rotor is better especially in small scale wind turbines where electronic systems are rarely used. Some of the benefit associated with this fact is lower nacelle weight, less noise and vibrations, low power loss and less service required at the nacelle. The PM generator that was used in this study has eight pole pairs with 1 $\mathrm{kW}$ power output (private communication with Matia (2012), the native technician who fabricated the generator).

\section{METHODS AND MATERIALS}

The synchronous permanent a.c. generator locally fabricated in Tanzania was characterized and analyzed using both experimental and analytical methods. The generator was designed with the following technical characteristics:

(a) Rated power: $1 \mathrm{~kW}$,

(b) Maximum rated rotor speed 200 rpm,

(c) Rated speed $8 \mathrm{~m} / \mathrm{s}$,

(d) Maximum power: $1.5 \mathrm{~kW}$,

(e) Output voltage : $12-64 \mathrm{~V}$,

(f) Cut in wind speed $3.5 \mathrm{~m} / \mathrm{s}$, and 
(g) Cut out wind speed $30 \mathrm{~m} / \mathrm{s}$.

Two factors namely rotational speed (rpm) and load resistance $(\mathrm{Ohm})$ were identified for the experiments. Each factor has nine levels resulting into a total of 81 experiments conducted in set combinations. The values of rotational speed and load resistance shown in Table 1 were recorded through experimental trials, which aimed at determining their operational ranges. The trials were done repeatedly for error minimization and to have the precise ranges of rotational speed and load resistance.

Table 1: Design of experiment based on rotational speed and load resistance

\begin{tabular}{cccccccccc}
\hline \multirow{2}{*}{ Factors } & \multicolumn{10}{c}{ Factor levels } \\
\cline { 2 - 10 } & 1 & 2 & 3 & 4 & 5 & 6 & 7 & 8 & 9 \\
\hline $\begin{array}{c}\text { Rotational Speed } \\
(\text { rpm) }\end{array}$ & 79.9 & 116 & 144.2 & 183.3 & 223 & 261 & 274 & 340 & 371.4 \\
$\begin{array}{c}\text { Load Resistance } \\
(\text { Ohm })\end{array}$ & 17.9 & 18.2 & 18.6 & 19 & 19.5 & 19.8 & 20.2 & 20.5 & 21.1 \\
\hline
\end{tabular}

The experimental set-up was as shown in Figure 1(a) and Figure 1(b). The thyristor converter supplied the power to the DC machine which was a prime mover. The rotational speed of the DC machine was measured by hand held tachometer (S), which is also noted as (9) in Figure 1(a). This was done through reflecting tape (7) attached to coupling (10) as shown in the Figure 1(a) and Figure 1(b). The rotational speeds were recorded after varying the load resistance from 17.9 to 21.1 Ohms in nine steps. The variation of load resistances was carefully monitored for the safety of the generator. As observed in the figures, the fixed resistive load (1) was valued 16 Ohms and attached in each phase of the generator separately as the generator has three phase. Each phase was attached also separately to the variable resistance (2) which was set to vary from 1.9 to 5.1 Ohms. Hence, each phase was varied from 17.9 to $21.1 \mathrm{Ohms}$ equally. The output current was recorded through power meter (3) and the values of voltage per phase were recorded through voltmeter (4). At the same time readings for the frequency were taken using multimeter (4) and oscilloscope (5). On the other hand, the reading of the voltage and current of the DC machine (8) were simultaneously taken in each step change of rotational speed and variable resistance. The locally fabricated generator is indicated by number (6).

The experiment started by running the generator with no load. The variation of the rotational speed was done while taking the readings of output voltage of generator and at the same time the value of the DC voltage and current was recorded in the thyristor converter. At this stage of experiment, the values of phase resistances were measured for both generators and the internal resistance of the DC machine. The experiment was conducted again with load, while varying the resistance in the nine steps for each stage of rotational speed. The speed was also varied in nine stages, while taking the readings of output voltage and current for the generator. The input values of DC voltage and current was also recorded. The electric circuit representation of the experimental set up and mode of data recording is shown in Figure 2.

From the data recorded during the experiment the following parameters of the generators were realized:

(i) Generator output power,

(ii) Mechanical input power from the DC machine, and

(iii) Generator efficiency. 
The arrangement of the AC generator, DC machine and thyristor converter is shown in Figure 3 while the equivalent circuit of the DC Machine is shown in Figure 4. The equivalent circuit was employed in the analysis of the AC generator. All sets of experimental tests were conducted at the Department of Electrical Power Engineering, Chalmers University of Technology in Sweden. The data collected was analysed using Matlab and Origin Pro software packages.

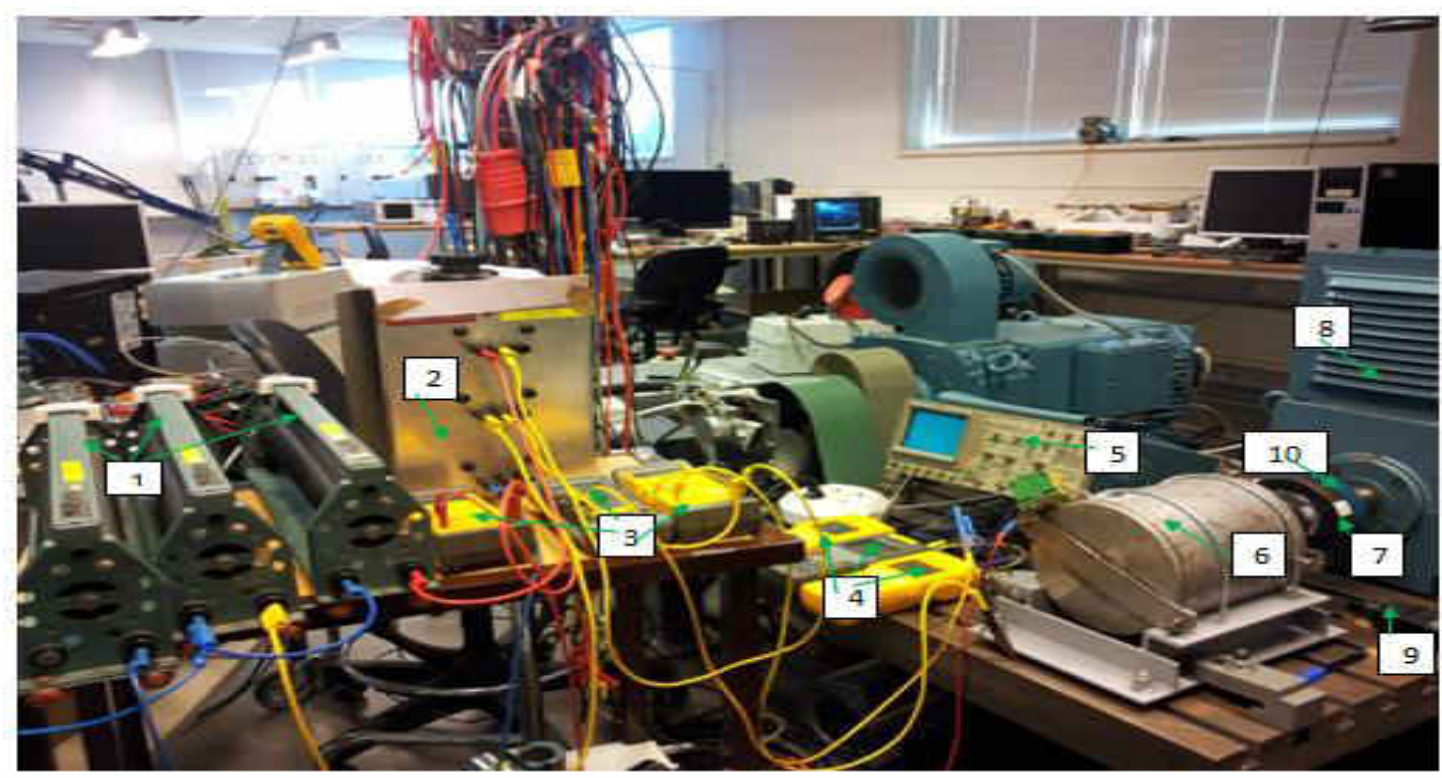

Figure 1(a): $\quad$ Pictorial representation of the laboratory experimental set-up

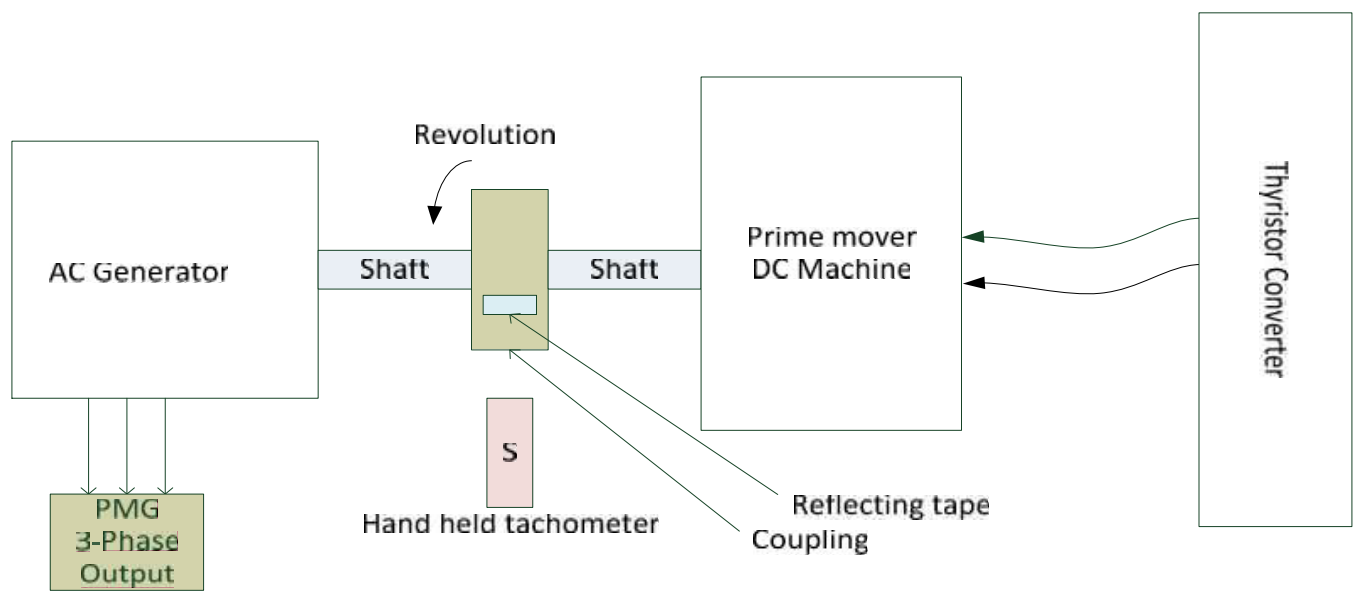

Figure 1(b): $\quad$ Schematic experimental set-up of AC generator 


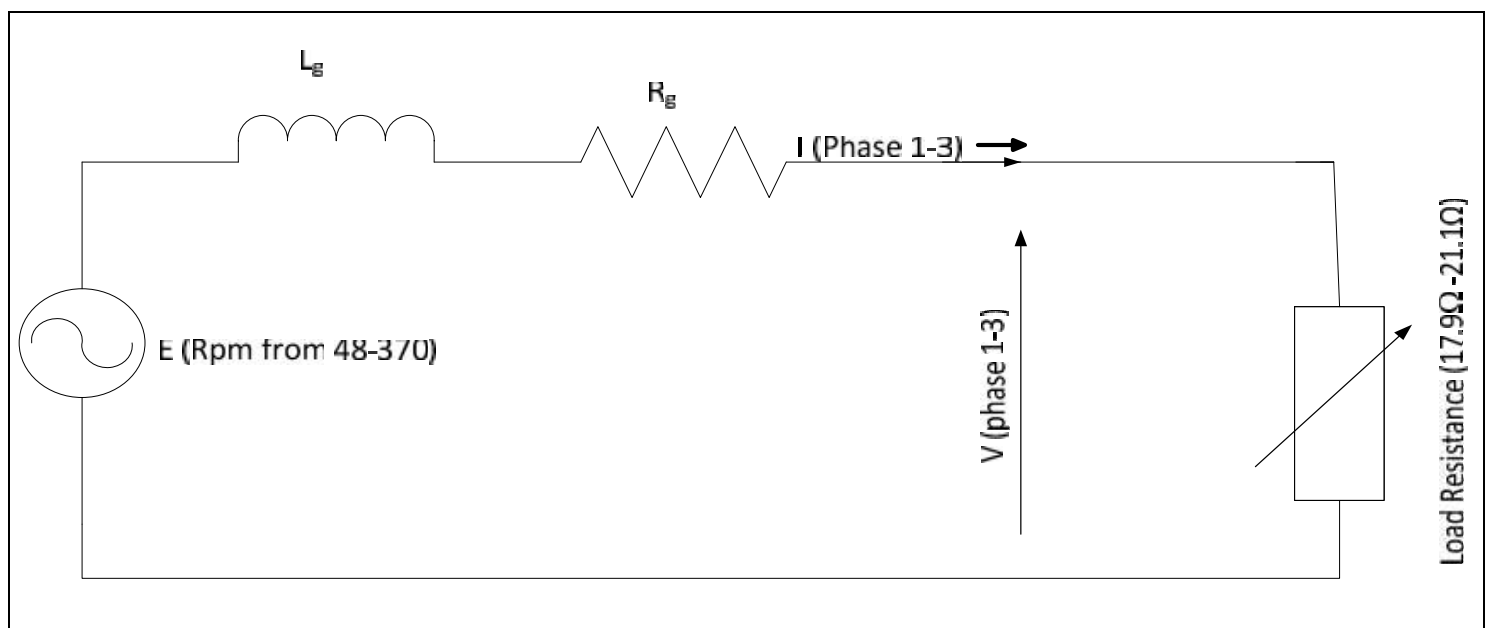

Figure 2: $\quad$ Circuit diagram of generator test

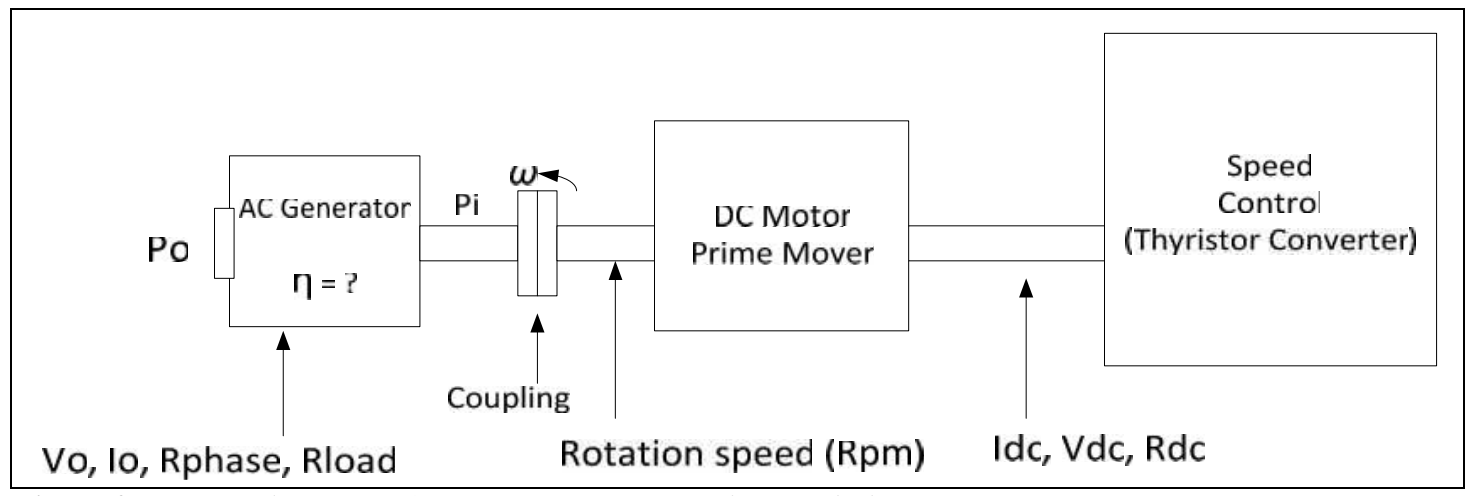

Figure 3: $\quad$ Alignment of AC generator, DC machine and Thyristor converter

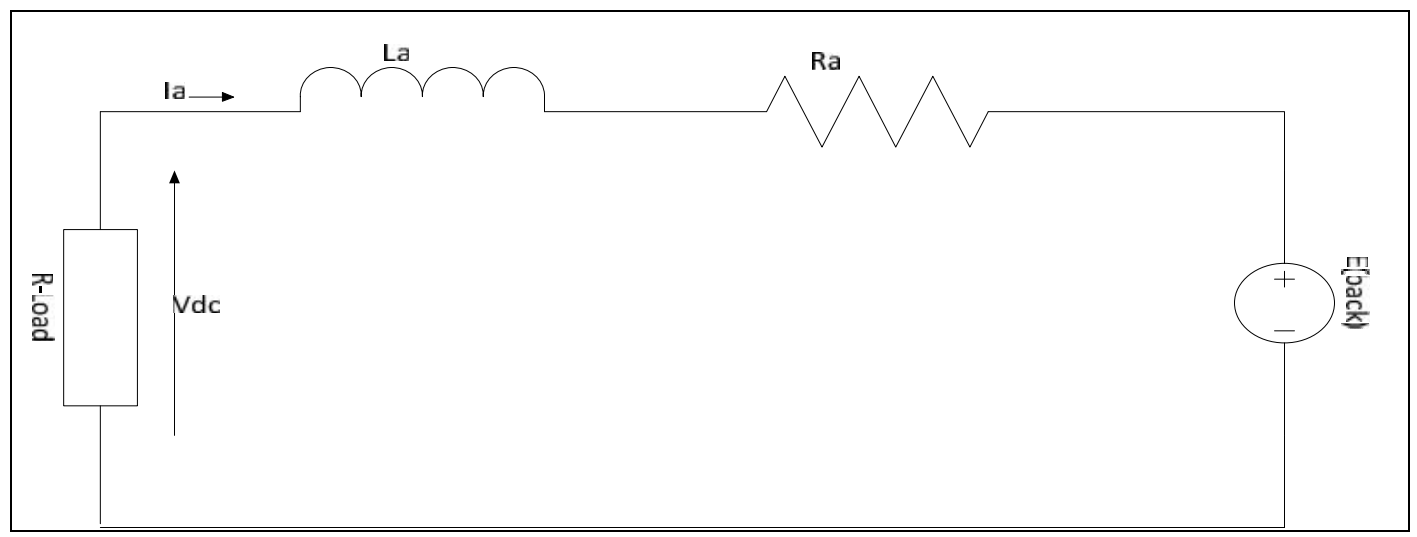

Figure 4: $\quad$ Equivalent circuit of the DC Machine

THEORETICAL CONCEPTS

Data which were measured in the DC machine included armature current $\left(I_{a}\right)$, armature voltage $\left(V_{a}\right)$, revolution per minute $(\omega)$ and internal resistance of DC machine $\left(R_{d c}\right)$. Equation (3) was used for estimation of armature voltage $\left(\mathrm{V}_{\mathrm{a}}\right)$ (Henneberger, 2005; Mohamed, 2000):

$V_{a}=I_{a} R_{d c}+E_{b a c}$

where $E_{b a c}$ is back emf produced by the DC Machine. 
But back emf can also be expressed as:

$$
E_{b a c}=\omega K \phi
$$

where $K \phi$ is a DC machine constant.

The value of $R_{d c}$ which is a DC Machine Resistance was directly measured by multi-meter. By substituting Equation (4) into Equation (3), $V_{a}$, can be represented by equation (5).

$$
V_{a}=I_{a} R_{d c}+\omega K \phi
$$

By making DC machine constant $K \phi$ the subject, equation (6) was obtained.

$$
K \phi=\frac{V_{a}-I_{a} R_{d c}}{\omega}
$$

The Torque $T_{e}$ can then be calculated using equation (7).

$$
T_{e}=K \phi I_{a}
$$

The mechanical input power $\left(P_{i}\right)$ to generator can be calculated using equation 8 .

$$
P_{i}=T_{e} \omega
$$

Equation (9) was obtained by substituting $T_{e}$ from Equation (7) into equation (8).

$$
P_{i}=K \phi I_{a} \omega
$$

For the standard procedures the value of $\omega$ should be divided by 60 to have $\mathrm{rad} / \mathrm{sec}$ (i.e. $\omega / 60 \mathrm{rad} / \mathrm{sec}$ ). For the AC generator, electrical output power can be obtain from equation (10).

$$
P_{o}=V_{o} I_{o}
$$

But for delta connections, line voltage $\left(V_{L}\right)$ is equal to phase voltage $\left(V_{p h}\right)$ so that:

$$
V_{L}=V_{p h}
$$

The line current $\left(I_{L}\right)$ is equal to $I_{p h} \sqrt{3}$ which can thus be expressed as:

$$
I_{L}=I_{p h} \sqrt{3}
$$

Substituting Equations (11) and (12) in Equation (10), electrical power output can be calculated using equation (13).

$$
P_{\text {out }}=V_{p h} I_{p h} \sqrt{3}
$$

Based on the derived theoretical concepts, the efficiency can now be calculated by substituting Equations (9) and (13) in Equation (2).

\section{RESULTS AND DISCUSSION}

The characteristic curve of voltage against rotational speed for the AC generator with no load resistance is shown in Figure 5. The graph shows that there is a linear relationship between the two variables. The maximum output voltage was about $65 \mathrm{~V}$, a value that was obtained at the rotational speed of about $350 \mathrm{rpm}$. As depicted in Figure 6, the same linear relationship was obtained when a load resistance was applied to the generator. The maximum voltage was about $40 \mathrm{~V}$, a value that was observed at the rotational speed of about $300 \mathrm{rpm}$.

The characteristic graph of output power against rotational speed is shown in Figure 7 for load resistances 21.9, 19.5 and $17.9 \Omega$. The graph shows that output power is not linearly related to rotational speed. The graph indicates that the maximum output power was $80 \mathrm{~W}$, the value that was attained at the rotational speed of about $300 \mathrm{rpm}$.

The efficiency of the generator as a function of voltage and rotational speed are respectively depicted in Figure 8 and Figure 9. It is indicated in Figure 8 that the efficiency of the generator is about $55 \%$ against voltage. As noted in the figure, this value is more or less similar for all the resistances used in the experiment. The figure further shows that the efficiency of the machine decreases as the resistance increases. At a voltage of about $10 \mathrm{~V}$, the efficiency reaches the maximum. Figure 9 on the other hand 
shows that the efficiency against rotational speed has similar trend of that against voltage in Figure 8. In similar manner, the efficiency as a function of rotational speed tends to decrease as resistance increases. The maximum efficiency is attained at the rotational speed of about $80 \mathrm{rpm}$.



Figure 5: $\quad$ Measured voltage against rotational speed with no load

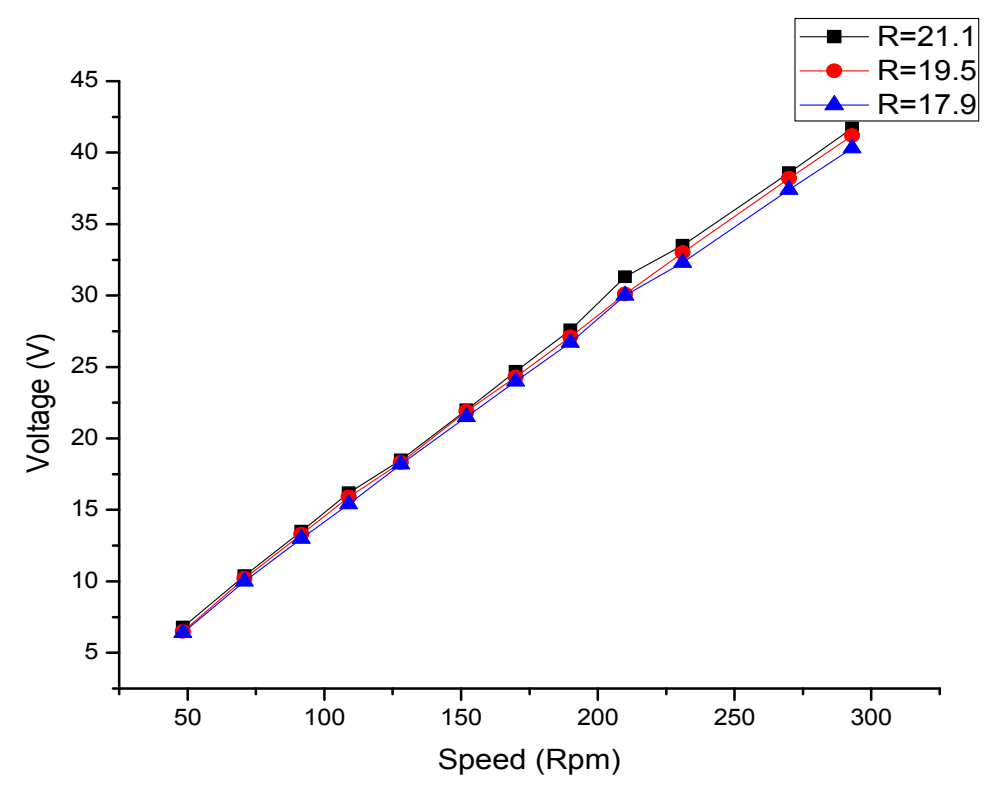

Figure 6: $\quad$ Measured Voltage against rotational speed with load resistance 


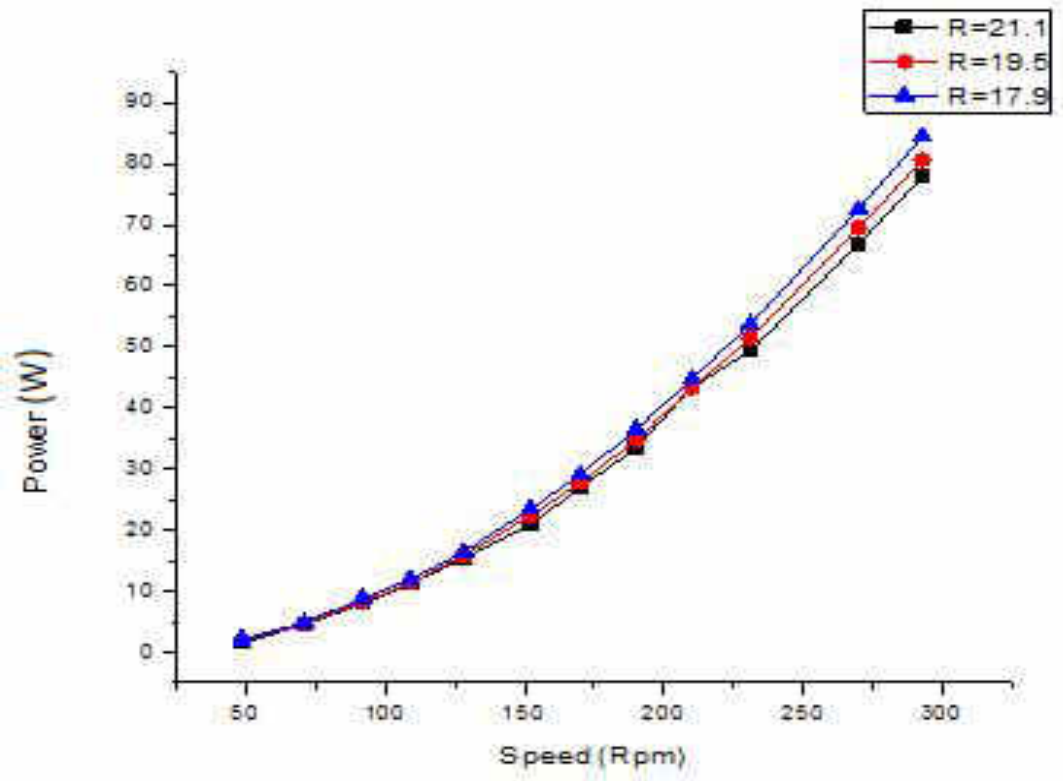

Figure 7: $\quad$ Output power against rotational speed with variable load resistance

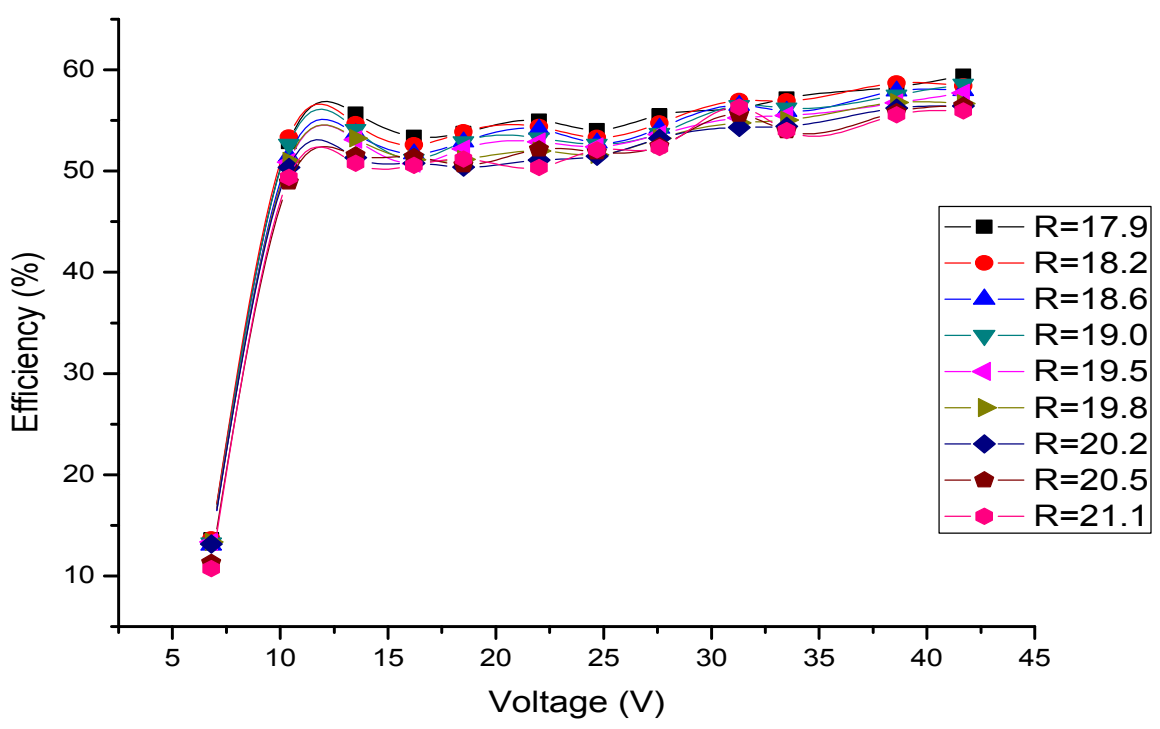

Figure 8: $\quad$ Efficiency against voltage with variable resistance 




Figure 9: $\quad$ Efficiency against rotational speed with variable resistance

\section{CONCLUSIONS}

This study has highlighted the experimental design for the analysis of power efficiency of the synchronous permanent AC generator locally fabricated in Tanzania. The main idea was to determine the power efficiency of the generator in respect to voltage and rotational speed at varying load resistance. The locally fabricated generator was mounted on the test rig and tested. To accomplish the study, the experiments were designed to characterise the combinations of load resistance and rotational speed each in nine levels of these two variables. The results show that there is a linear relationship between voltage and rotational speed of the generator with and without the existence of load resistance. The results further indicate that there is no linear relationship between output power and rotational speed. The power efficiency of the local generator is about 55\% against the output voltage as well as the rotational speed. This efficiency seems to be low and as such necessary efforts should be devoted to improve it. It is also recommended that the actual field test be conducted to confirm the system performance in the real environment.

\section{ACKNOWLEDGMENT}

The authors wish to thank the Sida Renewable Energy Programme of the University of Dar es Salaam for funding this research. The authors would also like to thank Mr. Joseph Matia for providing the fabricated wind turbine generator used in the experimental study. Many thanks are directed to Dr. S.G.J. Ehnberg of the Department of Electric Power Engineering, Chalmers University of Technology in Sweden for his sincere assistance in developing the experimental set-up in the laboratory.

\section{REFERENCES}

Hansen, L. Helle, F. Blaabjerg, E. Ritchie, S. Munk- Nielsen, H. Bindner, P. Sørensen and B. Bak-Jensen Ris $\varnothing$, (2001). Conceptual survey of Generators and Power Electronics for Wind Turbines, L.H. National Laboratory, Roskilde, Denmark.

Henneberger, G. (2005). Electrical Machines I, Basics, Design, Function, 
Operation based on a Lecture at Stiebler, M. (2008). Wind Energy Aachen University.

Systems for Electric Power

Johnson, L.G. (2006). Wind Energy Generation. Inst. of Energy and Systems: Electronic edition. Automation Technology Einsteinufer 11, D-10587 Berlin Germany.

Mohamedi, A. (2000). Fundamentals of Electric Drives. Cole Publishing Company USA.

Vongmanee, V. (2009). Emulator of Wind Turbine Generator Using Dual Inverter Controlled Squirrel Cage Induction Motor. University of the Thai Chamber of Commerce, Bangkok, Thailand. 